\title{
New antimicrobial compounds from a marine-derived Bacillus sp.
}

Mohamad Abdul Mojid Mondol, Fakir Shahidullah Tareq, Ji Hye Kim, Min Ah Lee, Hyi-Seung Lee, Jong Seok Lee, Yeon-Ju Lee and Hee Jae Shin

The Journal of Antibiotics (2014) 67, 605-606; doi:10.1038/ja.2014.77

Correction to: The Journal of Antibiotics (2013) 66, 89-95; doi:10.1038/ja.2012.102; published online 5 December 2012

The authors of the above Article noted an error in publication of this paper in Figures 2, 3 and 5, whereby the wrong bond was used to show the configuration of $\mathrm{C}-19$ in macrolactin $\mathrm{X}$ (1). The absolute configuration of $\mathrm{C}-19$ in $\mathbf{1}$ was $S$ but drawn as $R$ in Figures 2, 3 and 5. An extra methyl group was found in 2 at C-22 in Figure 2 as well. The corrected figures and legends are shown below.

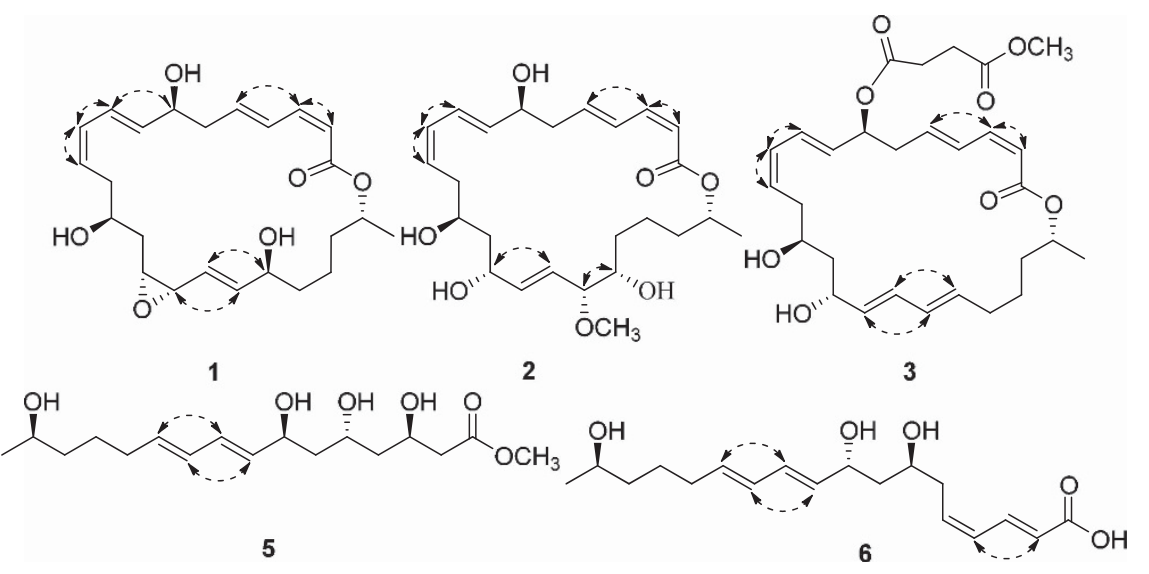

Figure 2 Key ROESY correlations for $\mathbf{1 - 3 , 5}$ and 6 .

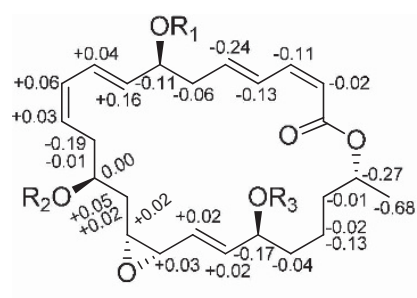

1a: $\mathrm{R}_{1}=\mathrm{R}_{2}=\mathrm{R}_{3}=(S)-M T P A$ 1b: $\mathrm{R}_{1}=\mathrm{R}_{2}=\mathrm{R}_{3}=(R)-M T P A$

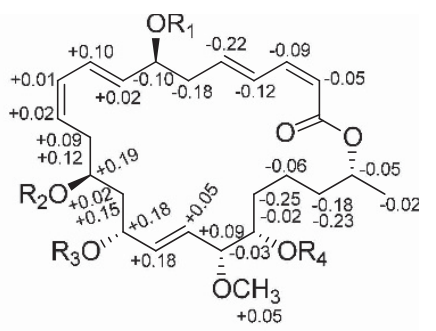

2a: $\mathrm{R}_{1}=\mathrm{R}_{2}=\mathrm{R}_{3}=\mathrm{R}_{4}=(S)$-MTPA

2b: $\mathrm{R}_{1}=\mathrm{R}_{2}=\mathrm{R}_{3}=\mathrm{R}_{4}=(R)-$ MTPA $\underbrace{\text { OR }}_{+0.5} \underbrace{-0.06}_{-0.30} 12\}_{-0.02}^{2 b} \xi$

5a: $\mathrm{R}=(S)-M T P A$

5b: $\mathrm{R}=(R)-\mathrm{MTPA}$

Figure $3 \Delta \delta_{\mathrm{H}}$ values $\left(\Delta \delta_{\mathrm{H}}=\delta_{S}-\delta_{R}\right)$ obtained for $(S)$ - and -(R)-MTPA esters of $\mathbf{1 , 2}$ and $\mathbf{5}$. 


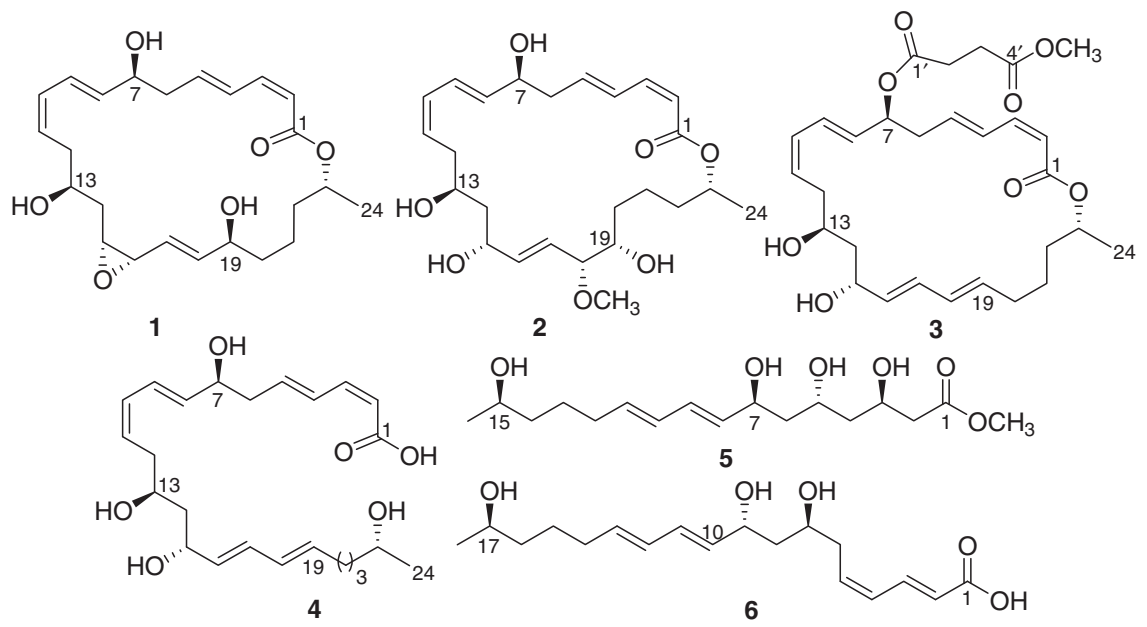

Figure 5 Chemical structures of antimicrobial compounds $\mathbf{1}-\mathbf{6}$. 